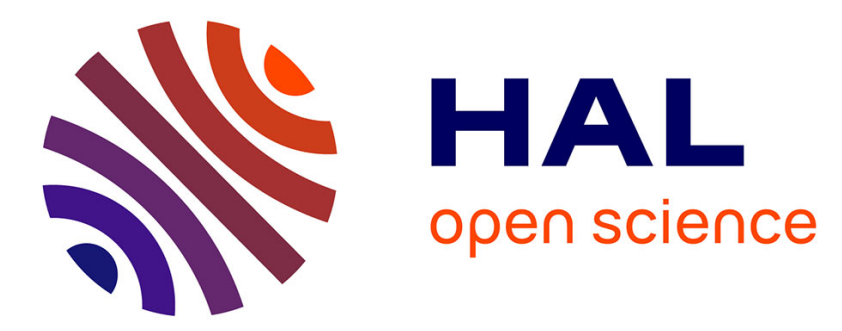

\title{
Development of novel h-BNNS/PVA porous membranes via Pickering emulsion templating
}

\author{
Danae Gonzalez-Ortiz, Céline Pochat-Bohatier, Sana Gassara, Julien
}

Cambedouzou, Mikhael Bechelany, Philippe Miele

\section{- To cite this version:}

Danae Gonzalez-Ortiz, Céline Pochat-Bohatier, Sana Gassara, Julien Cambedouzou, Mikhael Bechelany, et al.. Development of novel h-BNNS/PVA porous membranes via Pickering emulsion templating. Green Chemistry, 2018, 20 (18), pp.4319 - 4329. 10.1039/c8gc01983e . hal-01895408

\section{HAL Id: hal-01895408 \\ https://hal.umontpellier.fr/hal-01895408}

Submitted on 4 Jun 2021

HAL is a multi-disciplinary open access archive for the deposit and dissemination of scientific research documents, whether they are published or not. The documents may come from teaching and research institutions in France or abroad, or from public or private research centers.
L'archive ouverte pluridisciplinaire HAL, est destinée au dépôt et à la diffusion de documents scientifiques de niveau recherche, publiés ou non, émanant des établissements d'enseignement et de recherche français ou étrangers, des laboratoires publics ou privés. 


\title{
Development of novel h-BNNS/PVA porous membranes via Pickering emulsion templating
}

\author{
Danae Gonzalez Ortiz ${ }^{\mathrm{a}}$, Céline Pochat-Bohatiera, Sana Gassaraa, Julien Cambedouzoub, Mikhael \\ Bechelany*a, Philippe Miele*a,c

\begin{abstract}
Polymer-based membranes play an important role in water filtration, in particular in the removal of particles, microorganisms and organic pollutants. Developing a reliable fabrication method for membranes presenting both high flux and good selectivity remains challenging. Polyvinyl alcohol (PVA) is a well-known polymer with promising perspectives due to its specific properties such as nontoxicity, biocompatibility and biodegradability susceptible to be of great interest within the context of developing green technologies. Herein, a new strategy using mainly water as solvent to produce porous membranes based on PVA has been developed using emulsion templating involving hexagonal boron nitride nanosheets ( $\mathrm{h}$ BNNS) as stabilizer. The membranes displaying a pore size around $1 \mu \mathrm{m}$ show a water performance over $2000 \mathrm{~L} \mathrm{~m}^{-2} \mathrm{~h}^{-1} \mathrm{bar}^{-1}$ and a rejection efficiency of $\sim 100 \%$. Moreover, the membranes did not significaly reduce their perfomance after particles filtration. The results indicated that the h-BNNS/PVA porous membranes fabricated via Pickering emulsion templating, are good candidates to be used as microfiltration membranes.
\end{abstract}

\section{Introduction}

Water pollution is one of the most serious issues in the entire world. Today, the availability of clean water is becoming a challenging task. ${ }^{1}$ Researchers emphasize to address these problems with the development of more effective and lower cost methods for water purification, while minimizing the use of hazardous chemicals and subserve the environment.

Membranes are becoming an important key for water treatment in different areas (drinking water purification, seawater desalination and wastewater treatment). Currently, polymeric membranes are the most widely used for water treatment due to their easy-forming properties, good flexibility, high perm-selectivity and low cost compared to inorganic membranes. However, there are still several challenges such as the trade-off between permeability and selectivity and the resistance to fouling. The development of new procedures to obtain porous membranes that meet those criterias are still needed. The manufacturing of porous membranes made with hydrophilic polymers present two main advantages: it reduces the organic solvent volume and increases the membrane fouling resistance.

Porous polymeric membranes have a wide range of applications spanning from water filtration ${ }^{2}$, pharmaceutical purification ${ }^{3}$, and battery separators ${ }^{4}$ to scaffolds for tissue engineering. ${ }^{5}$ Depending on the pore size, the membranes can be classified into microfiltration (MF), ultrafiltration (UF) and nanofiltration (NF) or reverse osmosis (RO). A wide range of polymers can be used, such as cellulose derivatives, ${ }^{6}$ polyvinylidene difluoride (PVDF), ${ }^{7}$ polysulfone (PS), ${ }^{8}$ polyacrylonitrile $(\mathrm{PAN})^{9}$ and polyvinyl alcohol (PVA). These polymer-based membranes can be tailored to the specific needs of the process, and they can be used in many separation processes in industry. Among them, PVA polymer possesses highly hydrophilic character, excellent film-forming properties and outstanding physical and chemical stability. PVA could thus be considered as an intelligent material with unique properties that could be tailored in function of the use interest.

In the last decades, different techniques have been developed for forming PVA porous membranes. The oldest and most common technique described in the literature is the so-called 'phase separation'. It consists of forming a concentrated solution of the polymer in a solvent, subsequently the polymer membrane was immersed into a liquid bath in which the solvent is miscible but the polymer is not. ${ }^{10}$ An analogous procedure is the thermally induced phase separation (TIPS) but it plays with the temperature to form the membrane rather than a nonsolvent to coagulate the polymer. Recently PVA porous membranes were prepared by combining TIPS with temperature rise above the lower critical solution temperature (LCST) and chemical cross-linking with glutaraldehyde. ${ }^{11}$ Another strategy consists in developing PVA nanofibrous membranes using electrospun methods, in this case the membrane matrix is fibrous instead of layered. ${ }^{12}$ To the best of our knowledge all these techniques fail to control the porosity of the PVA-based membranes.

In the recent years, the development of porous materials using templating methods has drawn the scientists attention for their potential applications in different areas such as supports for

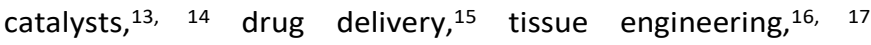
membranes for separation processes, ${ }^{18,19}$ and as templates for the production of inorganic materials. ${ }^{20}$ Although several methods have been reported on the fabrication of porous polymers, ${ }^{21-23}$ emulsion templates attract great attention owing to the facile tailoring of pore size and distribution of the polymer materials. In a typical emulsion templating scenario, a biphasic system is generated, and then the continuous phase is polymerized. The colloidal entities serve to create the porosity of the final polymeric material. Depending on the nature of colloidal system employed the pore size can be tuned from a few nanometres to hundreds of micrometres.

Emulsion templating methods represent an attractive route to produce highly porous and permeable polymeric materials with a well-defined porosity. The process has been known since the 1960's when Bartl et al. described the polymerization of styrene in an "inverse emulsion" (w/o) with as much as $83 \%$ internal aqueous phase, resulting in a cellular structure whose cells contained the dispersed water phase. ${ }^{24}$ Few years after, Lissant et al. described the term "high internal phase ratio emulsions" or "HIPE emulsions" when they prepared systems with over 
90\% monodisperse internal phase droplets and produce a 'solid-polymer-water emulsion'. ${ }^{25}$ The inconvenient of conventional HIPE's is they are commonly stabilized by surfactants and amphiphilic polymers, which are toxic and not environmentally friendly. A large amount of surfactants is required to produce stable HIPE's (5-50 wt.\% relative to continuous phase), ${ }^{26}$ and they generally show weak mechanical strength. ${ }^{27}$

In this work, we focus our attention on the development of porous PVA membranes using Pickering emulsions as soft templates. This method offers a sustainable advantage of avoiding the use of surfactants and the sintering steps since no solid organic material is introduced to produce the desired material. Moreover, Pickering emulsions possess many unique features with regards to emulsions stabilized by surfactants, such as superior stability and low toxicity. The higher stability of solid particles stabilized emulsions is due to their irreversible adsorption at the liquid-liquid interface, thus reducing the energy of the system. The particles form a rigid shell around the droplets and prevent emulsion breaking-up or coalescence. After removal of the droplet phase, a spherical void is left behind in the matrix. Many different types of colloidal materials, including silica, ${ }^{28,29}$ titania, $^{30,31}$ alumina, ${ }^{32}$ iron oxide nanoparticles ${ }^{33}$ or two-dimensional materials, such as graphene oxide $^{34,35}$ or hexagonal boron nitride $(\mathrm{h}-\mathrm{BN})^{36}$ have been used for the fabrication of materials from Pickering emulsions.

Among them, h-BNNS have attracted recently great interest due to their high surface area and their outstanding properties such as high-temperature stability, enhanced oxidation resistance, high hardness, high corrosion resistance and large thermal conductivity. ${ }^{37}$ Furthermore, the incorporation of inorganic nanoparticles into the polymeric matrix improve the hydrophilicity, antifouling, and water permeability. ${ }^{38}$ However, the direct incorporation into the membrane casting solution leads to particle agglomeration and poor compatibility between the inorganic nanoparticles and the polymeric matrix. ${ }^{39}$ The addition of h-BNNS to a polymeric matrix using Pickering emulsion method has the advantage to avoid the nanosheets aggregation. The nanosheets are irreversibly adsorbed at the water-oil interface, and they will provide, a defined porosity and enhanced mechanical properties to the nanocomposite.

Herein, we present a novel and sustainable approach to prepare h-BNNS/PVA porous membranes by an emulsion templating strategy. By this procedure, membranes with different pore sizes distributions were obtained by tuning the curing time of cast emulsions before cross-linking. The membranes morphologies and their chemical and mechanical properties were investigated. The membranes pore size was determined by porometry and their performance in water permeability and particle rejection were also investigated. This is the first time that PVA-based porous membranes prepared via Pickering emulsions templating are reported. Furthermore, the process is clean and presents low enery requirements. It is not using any hazardous reagents, it takes place at ambient temperature and it prevents the generation of waste.

\section{Results and discussion}

An emulsion containing h-BNNS and PVA was prepared in a first step via ultrasonic power; here the exfoliated $h-B N N S$ is playing the role of emulsifiers stabilizing the emulsion. Then the $h-$ BNNS/PVA porous membranes were obtained by casting the emulsion onto a glass support and further crosslinking with GTA. This method allows the generation of porosity using Pickering emulsion as template.

\section{Exfoliated h-BNNS characterization}

The exfoliated h-BNNS obtained from bulk h-BN using assisted liquid phase exfoliation with ultrasonic power were characterized by TEM. The characterization of exfoliated $h$ BNNS obtained by liquid exfoliation were already reported elsewhere. ${ }^{40}$ The TEM images of the obtained h-BNNS are shown in Fig. S1. Fig. S1b (inset from Fig. 1a) reveals the thickness of a few-layered h-BNNS to be approximately $10 \mathrm{~nm}$, which corresponds to roughly a few tens of $\mathrm{BN}$ atomic layers, assuming that the $\mathrm{h}-\mathrm{BN}$ interlayer distance is $0.33 \mathrm{~nm}$. This value agrees with a semi-quantitative assessment of h-BNNS thickness through TEM analyses, which suggests an average thickness range of 6-10 $\mathrm{nm}$ for exfoliated h-BNNS. ${ }^{41}$ The lateral size is well preserved to be hundreds nanometres. ${ }^{36}$

\section{Synthesis and characterization of membranes}

The morphology of the PVA and h-BNNS/PVA membranes was analysed by SEM. Fig. 1 shows the cross-sections and surfaces images of the as-prepared membranes with $2 \mathrm{wt} . \% \mathrm{~h}-\mathrm{BNNS}$ and 15 wt.\% PVA at different curing times and also the membrane prepared from $15 \mathrm{wt} . \%$ PVA emulsion free of $\mathrm{h}$-BNNS. Different morphologies can be observed in their cross-sections as well as in their surfaces. The membranes prepared from free BN emulsions are dense; they do not present any signs of porosity either in their internal structure or surface (Fig. $1 \mathrm{a}-\mathrm{b}$ ). On the other hand, the membranes prepared from h-BNNS/PVA emulsion (Fig. $1 \mathrm{c}-\mathrm{h}$ ) present porosity depending on the curing time. When the membranes are cured for short term, it is observed that the membranes present a porous internal structure and surface. Depending on the exact curing time, the membrane morphology is different. The membranes cured for $1 \mathrm{~h} \mathrm{(Fig.} \mathrm{1g)} \mathrm{are} \mathrm{thicker} \mathrm{than} \mathrm{the} \mathrm{one} \mathrm{cured} \mathrm{for} 3 \mathrm{~h}$ (Fig. 1e) and the pore size is different (Supporting information Fig. S1). The pores of BNP-3h are smaller than the ones of BNP-1h. This fact is likely to be due to slow solvent evaporation (both water and ethyl benzoate) during the curing time that makes PVA chains come closer to each other, leading to a decrease in the pore size. The surfaces of the membranes BNP-1h and BNP-3h both present similar morphology but the pores on BNP-3h surface (Fig. 1f) are smaller than the pores on BNP-1h surface (Fig. 1h). Otherwise, when the membranes were cured for $24 \mathrm{~h}$, they do not present a defined porosity observable with this technique (Fig. $1 \mathrm{c}-\mathrm{d}$ ). Curing the membranes for long time may induce, as previously mentioned, both water and ethyl benzoate removal from the gel structure and could be responsible for a closer position of PVA chains leading to a total collapse of the pores. 

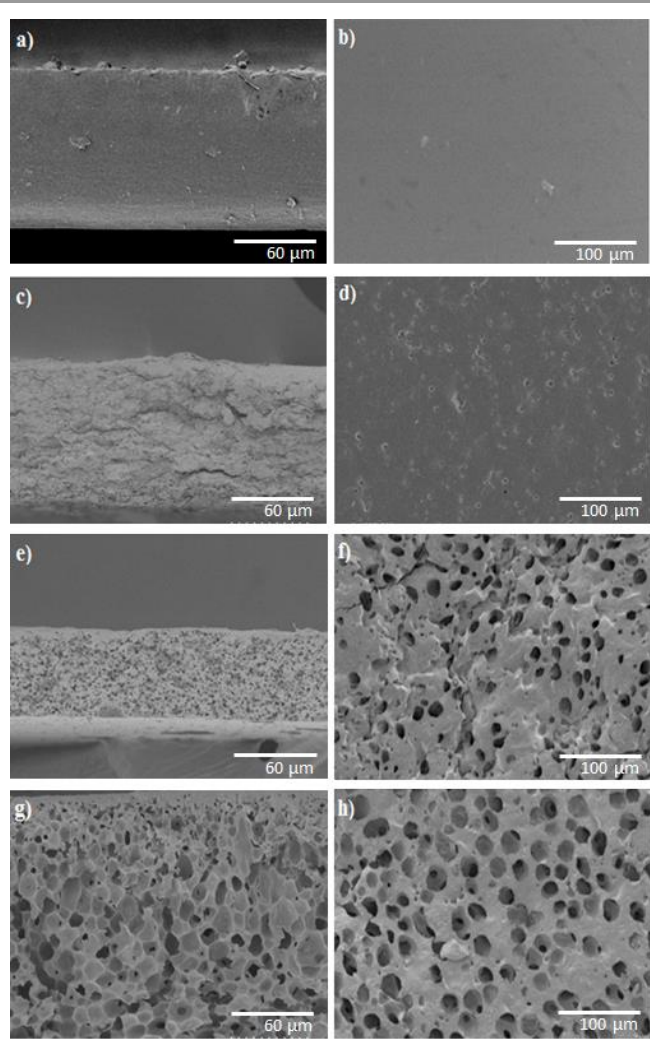

Fig. 1 SEM images of h-BNNS/PVA porous membranes depending on the curing time before crosslinking a) cross-section of single PVA b) surface of single PVA c) cross-section of BNP-24h d) surface of BNP-24h e) cross-section of BNP-3h f) surface of BNP-3h g cross-section of BNP-1h h) surface of BNP-1h

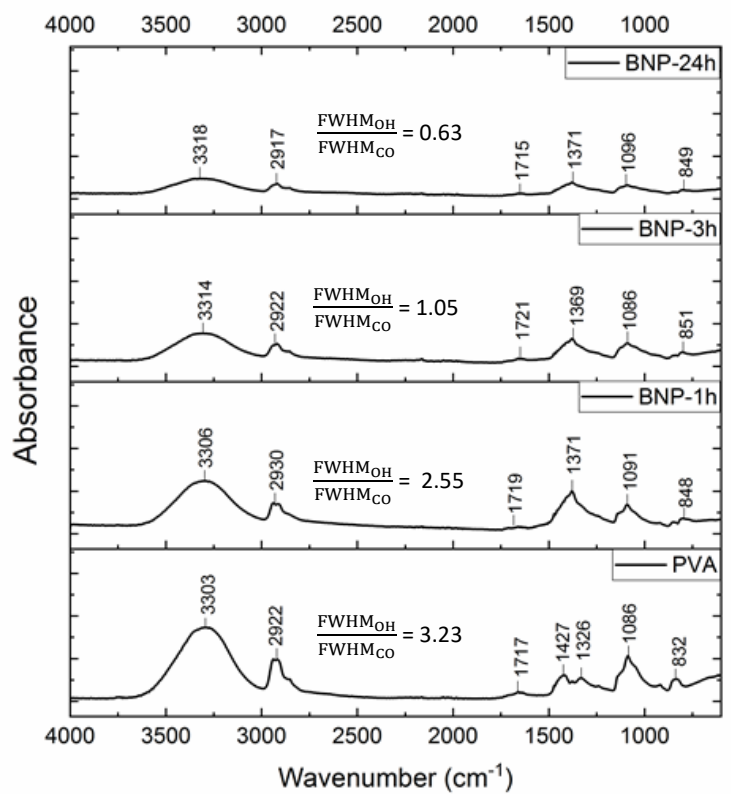

Fig. 2 FTIR spectra of PVA and h-BNNS/PVA membranes at different curing times a) PVA b) BNP-1h c) BNP-3h d) BNP-24h

The membranes were analysed by ATR-FTIR to determine the crosslinking effectivity. FTIR spectra of the PVA and hBNNS/PVA membranes with different curing times are shown in Fig. 2 The FTIR curve of the pure PVA membrane displays several characteristic bands, such as $\mathrm{OH}$ stretching vibration $\left(\mathrm{V}_{\mathrm{OH}}=3500\right.$ $\left.-3000 \mathrm{~cm}^{-1}\right)$ and $\mathrm{OH}$ out of plane deformation $\left(\mathrm{v}_{\mathrm{OH}}=920 \mathrm{~cm}^{-1}\right)$; the stretching vibrational band of the $\mathrm{CH}_{2}$ groups of the PVA backbone $\left(v_{\mathrm{C}-\mathrm{H}}=2940 \mathrm{~cm}^{-1}\right)$; the $\mathrm{C}=\mathrm{O}$ and $\mathrm{C}-\mathrm{O}$ stretching of acetate groups $\left(v_{\mathrm{C}=0}=1720 \mathrm{~cm}^{-1}\right.$ and $\left.v_{\mathrm{COC}}=1250 \mathrm{~cm}^{-1}\right)$; the deformation vibration of the $\mathrm{CH}_{3}$ groups in PVA structure $\left(\mathrm{v}_{\mathrm{C}-\mathrm{H}}=\right.$ $1420-1330 \mathrm{~cm}^{-1}$ ). Furthermore, the curves of the h-BNNS/PVA membranes display two main absorption peaks, additional to PVA peaks, of $h-B N$ ascribed to the out-of-plane bending $\left(v_{B-N}=\right.$ $850 \mathrm{~cm}^{-1}$ ) of $\mathrm{sp}^{2}$-bonded $\mathrm{B}-\mathrm{N}-\mathrm{B}$ and the in-plane stretching of $s p^{2}$-bonded $B-N\left(v_{B-N}=1380 \mathrm{~cm}^{-1}\right)$. During the crosslinking of PVA with GTA, the amount of hydroxyl functions decreases to create acetal functions, while the carbonyl functions are supposed to be constant as this peak is resulting from the vinyl acetate functions, which do not react with GTA. GTA add carbonyl functions but they are considered negligible since PVA is in excess over GTA and also since it evaporates during the reticulation process. M'Barki et al ${ }^{11}$ calculated the ratio of maximum intensity corresponding to peaks at $3330 \mathrm{~cm}^{-1}$ and $1720 \mathrm{~cm}^{-1}$ to give a relative indication on the cross-linking degree. A lower ratio implies a more important cross-linking degree according to the reduction of $-\mathrm{OH}$ related to alcohol functions. Indeed, here the ratio between the peak intensities of the hydroxyl functions at $3400 \mathrm{~cm}^{-1}$ and that of the $\mathrm{C}=\mathrm{O}$ of the ester function are compared to determine the apparent crosslinking effectivity in the surface. When the curing time increases from $1 \mathrm{~h}$ to $24 \mathrm{~h}$, SEM images revealed that membranes have a porosity loss. Indeed, this fact is related to the crosslinking effectiveness of the membranes.

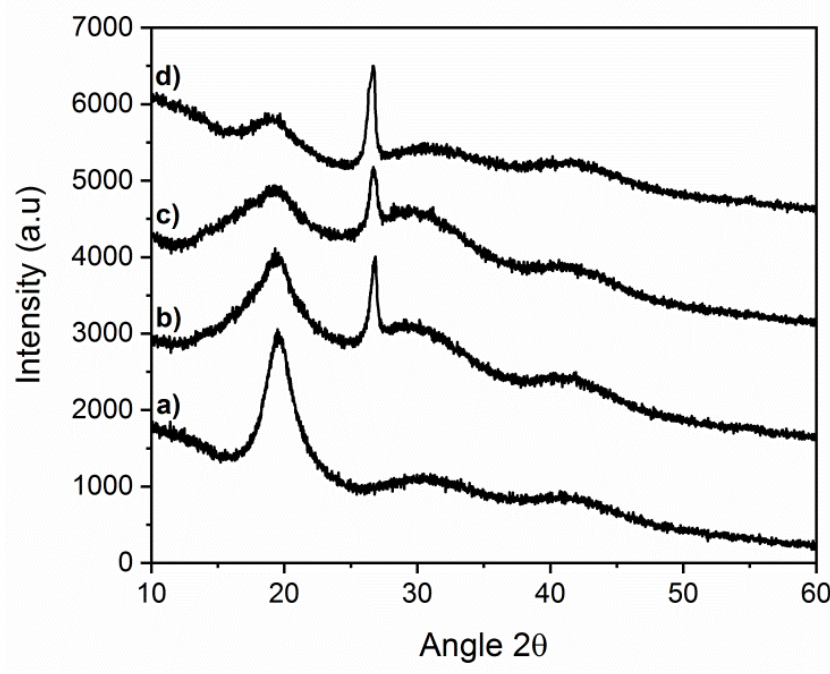

Fig. 3 XRD patterns of a) PVA b) BNP-1h c) BNP-3h and d) BNP-24h membranes

The ratio between the intensities of hydroxyl and carbonyl functions decreases from 3.23 to 0.63 as the membranes curing time increases from 1 to $24 \mathrm{~h}$. This reflects a higher effectivity crosslinking in the membrane which does not present porosity.

The XRD patterns of the obtained membranes prepared from pure PVA and h-BNNS/PVA emulsions are shown in Fig.3. The XRD patterns reveal a peak around $19.5^{\circ}$ suggesting the presence of a crystalline microstructure characteristic of PVA. The intensity of the peak decreases by adding h-BNNS to the samples and it also becomes broader. The XRD patterns of the obtained membranes prepared from pure PVA and h- 
BNNS/PVA emulsions are shown in Fig.3. The XRD patterns show a peak around $19.5^{\circ}$ suggesting the presence of a crystalline microstructure characteristic of PVA. The intensity of the peak decreases by adding h-BNNS to the samples and it also becomes broader. Moreover, there is a remarkable decrease of this peak intensity as the curing time of the membranes increases. This fact can be explained by the crosslinking effectiveness of each membrane, since higher is the crosslinking degree higher is the loss of crystallinity on the PVA microstructure. The XRD patterns of h-BNNS/PVA membranes show a peak around $2 \theta \sim 26.7^{\circ}$ characteristic of the (002) plane in $\mathrm{h}-\mathrm{BN}$. The FWHM values of the $\mathrm{h}-\mathrm{BN}(002)$ peak evidences the presence of exfoliated $\mathrm{h}-\mathrm{BN}$. Based on the Scherrer equation ( $\tau$ $=K \lambda / \beta \cos \theta$, where $\tau$ is the crystallite thickness, $K$ is a constant (typical value (0.9), $\lambda$ is the wavelength of $X$-ray and $\beta$ is the FWHM of the peak). The h-BNNS displays a thickness of $\sim 10 \mathrm{~nm}$. This result was confirmed by TEM images of isolated exfoliated h-BNNS.

The thermal degradation behaviour of PVA and h-BNNS/PVA membranes was examined by thermogravimetric analysis (TGA) as shown in Fig. 4. The PVA (grey curve) shows a quick weight loss of about $8 \%$ attributed to evaporation of not-bonded water present on the surface of the solids. More significant weight loss (15\%) in the temperature range of $150-250{ }^{\circ} \mathrm{C}$ is due to the PVA de-acetylation.

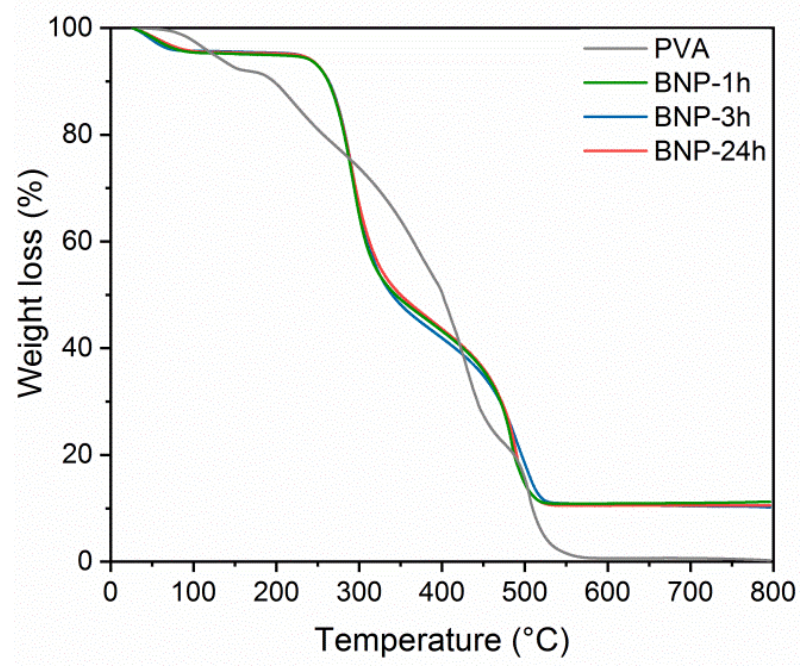

Fig. 4 Thermogravimetric analyses of PVA and h-BNNS/PVA membranes

The third region around $250-500{ }^{\circ} \mathrm{C}$ appeared to be due to degradation of the backbone of PVA composite polymer membrane with a total weight loss of about $55 \%$.The last degradation step of about $22 \%$ is due to the degradation of vinyl acetates groups. The h-BNNS/PVA curves at different curing times (1, 3 and $24 \mathrm{~h})$ display the same behaviours, so the porosity does not affect the thermal behaviour of the polymer membrane. The h-BNNS/PVA curves show the same transition regions than the pure PVA, albeit in different proportions. Notbonded water represents $3 \%$ weight loss. Degradation of the PVA backbone chain represents $50 \%$ of the weight loss and degradation of vinyl acetate groups is about $30 \%$ of the weight loss. It is observed in the h-BNNS/PVA curves a residual weight that the pure PVA is not displaying. This residual weight of $17 \%$ is due to the h-BNNS that are not degraded at $800^{\circ} \mathrm{C}$.

The DSC measurements were carried out under inert atmosphere at a scan rate of $10^{\circ} \mathrm{C} \mathrm{min}^{-1}$ by a heating-coolingheating cycle and the second heating curves were evaluated. The samples and the reference were heated from the same source and the differential of temperature was measured. During the measurements, the samples were first heated from -20 to $180{ }^{\circ} \mathrm{C}$, and they were cooled down to $0^{\circ} \mathrm{C}$. The second heating was performed between 0 and $180^{\circ} \mathrm{C}$ at a scan rate of $10^{\circ} \mathrm{C} \mathrm{min}^{-1}$. The glass transition temperature $\left(\mathrm{T}_{\mathrm{g}}\right)$ of the PVA and h-BN membranes was measured. The curve for PVA presents an endothermic peak at $124{ }^{\circ} \mathrm{C}$ corresponding to the $\mathrm{T}_{\mathrm{g}}$ temperature (Fig. 5). The peak is shifted to higher temperatures, around $130{ }^{\circ} \mathrm{C}$, for the h-BNNS/PVA membranes. One of the factors affecting the $T_{g}$ is the ease with which polymer chains can move. The more easily they move, a lower $\mathrm{T}_{\mathrm{g}}$ is display; a higher $\mathrm{T}_{\mathrm{g}}$ means more thermal energy is needed to induce the polymer chains motion. ${ }^{42}$ This result indicates that the addition of h-BNNS modifies the elastic behaviour of the composite by hindering the polymer matrix chains motion.

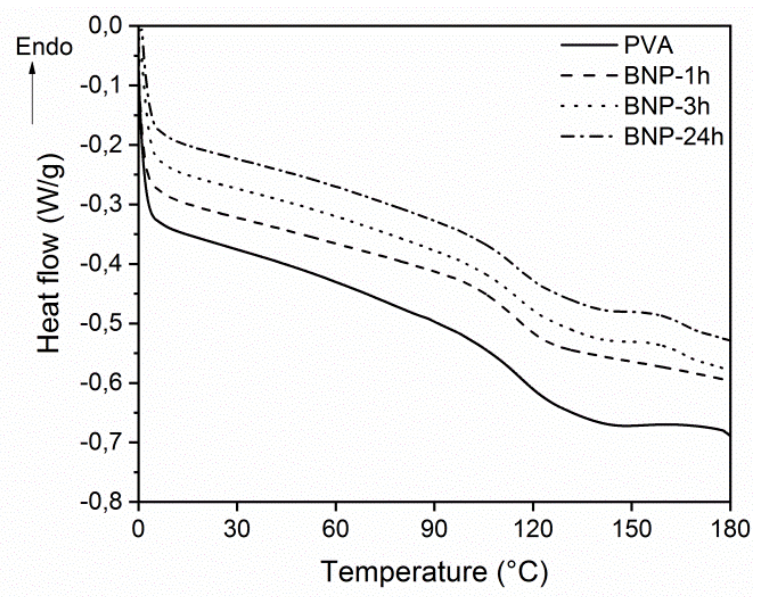

Fig. 5 DSC $2^{\text {nd }}$ cycle curves of PVA membrane and h-BNNS/PVA membranes at different curing times

The hydrophilicity of PVA and h-BNNS/PVA membranes was evaluated through WCA technique. The images (Fig. 6) show the different hydrophilic behaviour of the membranes. The membrane BNP-1h displays a contact angle of $48 \pm 2^{\circ}$. The WCA tends to increase with increasing curing times, the BNP-3h and BNP-24h display a contact angle of $57 \pm 2^{\circ}$ and $63 \pm 3^{\circ}$, respectively. The membrane prepared with pure PVA displays a higher contact angle $\left(70 \pm 2^{\circ}\right)$. The pictures were taken within the first $5 \mathrm{~s}$ after the water drop was deposited on the membranes. It was found that the water droplet was spread out and immediately penetrated into the water droplet was spread out and immediately penetrated into the membrane resulting in a change in the WCA approximately to $0^{\circ}$, except the BNP$24 \mathrm{~h}$ membrane for which the droplet takes a longer time to be completely absorbed by the membrane. These results could be explained by the fact that the BNP-1h and BNP-3h membranes possess porosity in their surface, allowing the water to be absorbed faster than the BNP-24h or PVA membranes which 
present a non-porous surface. The crosslinking effectivity also plays a role in the membrane hydrophobicity. When the membranes are crosslinked with GTA, the hydroxyl functions of the polymer structure react with aldehyde groups of the crosslinking agent and cause the membrane having a less hydrophilic behaviour. ${ }^{43}$ Hence, it is also important to point out that chemical crosslinking modifies PVA original network structure, and this significantly reduces the pore size distribution. The hydrophilicity of the membranes makes them favourable for applications in water purification.

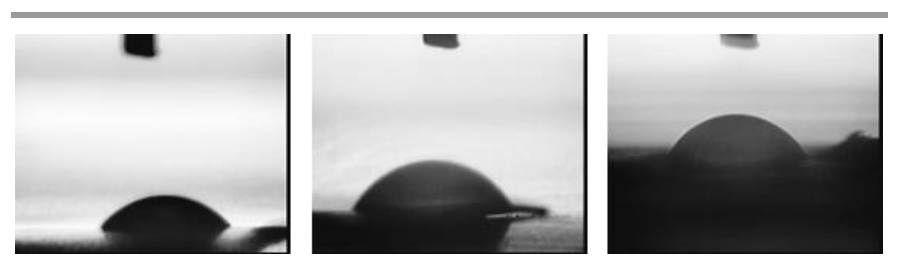

Fig. 6 WCA images of a) BNP-1h, b) BNP-3h and c) BNP-24h membranes

The swelling capacity of h-BNNS/PVA membranes in water was measured and the results are shown in Fig. 7. PVA is a water soluble polymer, hence crosslinking the membranes with GTA is essential for long-term application of membranes. Besides, the three membranes were crosslinked using the same method, but the time they were left to cure before crosslinking had an effect on their porosity, and therefore may affect their swelling behaviour. At first sight, all the membranes present similar swelling patterns. The swelling rate is fast at the beginning and then gradually slows down until a constant value after $3 \mathrm{~h}$ was reached. However, the BNP-1h membrane presents a higher swelling ratio than pure PVA, BNP-3h or BNP-24h membranes. This fact could be attributed, as mentioned previously, to surface porosity and also to the crosslinking effectivity. Increasing the porosity of the membrane leads to a faster water absorption and a higher water absorption capacity. Besides, higher crosslinking with GTA reduces the hydrophilicity behaviour, thus the membranes with higher crosslinking degree display lower swelling capacity.

\section{Elastic modulus and breaking strength}

The applied stress and elongation ratio curves of these samples are shown in Fig. 8. The corresponding Young modulus values, tensile strength and elongation to break ratio are illustrated in Table 1. The BNP-24h membranes possessed the highest Young modulus $(1180 \pm 31 \mathrm{MPa})$, the highest tensile strength $(14.6 \pm 0.1 \mathrm{MPa})$ and the lowest elongation at break (7.8 $\pm 0.2 \%)$. The BNP-1h and BNP-3h membranes exhibited much lower Young modulus, $229 \pm 28$ and $194 \pm 23 \mathrm{MPa}$, respectively; lower tensile strength, $7.3 \pm 1.4$ and $5.2 \pm 0.8 \mathrm{MPa}$, respectively; and higher elongation ratio at break, $10.3 \pm 0.1$ and $11.3 \pm 0.4 \%$, respectively. The comparison of the obtained results with pure PVA or PVA prepared in the presence of $h$ BNNS without the oil phase, shows that these membranes are more flexible. They possess a Young's modulus and tensile strength of $19 \pm 2$ and $6.9 \pm 1.4$, respectively.

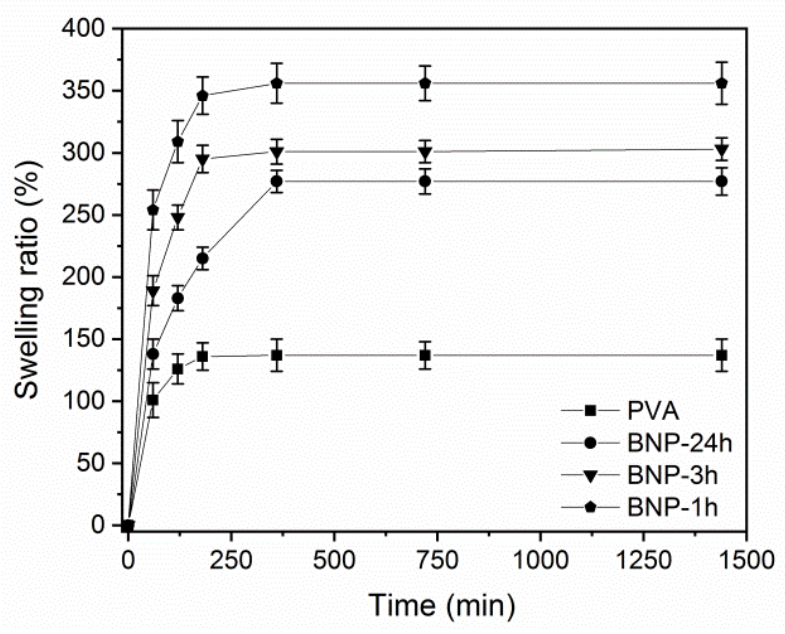

Fig. 7 Swelling ratio of pure PVA and h-BNNS/PVA membranes at different curing times.

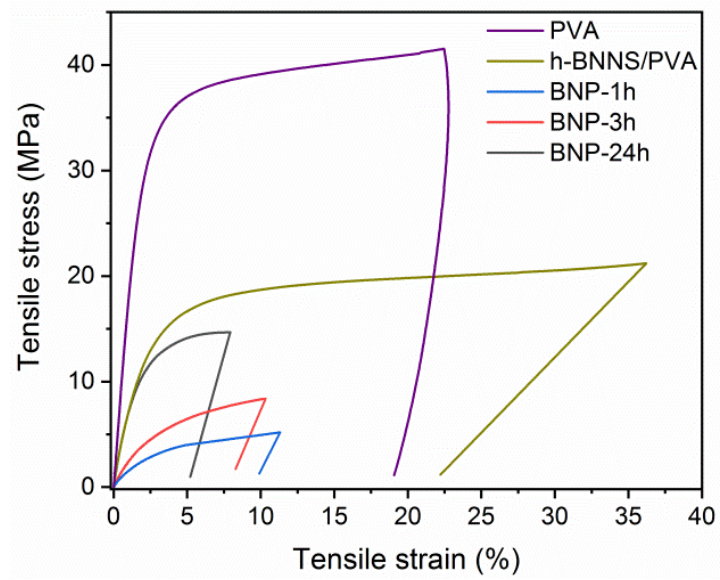

Fig. 8 Stress-strain curves of PVA, h-BNNS/PVA non-emulsified and h-BNNS/PVA membranes

Thus, the elongation at break is higher than the BNP $(1,3$ and $24 \mathrm{~h}$ ) membranes, with values of $22.6 \pm 0.4$ and $36.2 \pm 0.6$ for PVA and h-BNNS/PVA membranes. The above results might be explained first by the increase in porosity (in BNP-1h and BNP-3h) which significantly weakens tensile strengths and Young's modulus of the membranes. Secondly, the duration of curing time is significantly more important for the BNP-24h and influences its properties. The $\mathrm{Tg}$, as depicted by DSC measurements, is higher and thus water swelling ratio is lower. The porosity of this membrane at the surface is hardly visible by SEM. Mechanical results show that a longer curing time $(24 \mathrm{~h})$ conducts also to higher stiffness. These data associated to FTIR analyses converge on higher cross-linking degree of PVA chains for a $24 \mathrm{~h}$ curing time. Compared to other materials, our $\mathrm{h}$ BNNS/PVA membranes using the emulsion templating method display better mechanical properties than other PVA-based membranes obtained from TIPS or electrospun methods. The $h-$ BNNS/PVA membranes present higher young modulus (1180 \pm $31 \mathrm{MPa})$ and tensile strength $(14.6 \pm 0.1 \mathrm{MPa})$ compared to porous membranes fabricated using TIPS-LCST procedure, 301 $\pm 1 \mathrm{MPa}$ and $1.2 \pm 0.2 \mathrm{MPa}$ for Young modulus and tensile strength, respectively ${ }^{11}$. In the same way, the mechanical properties were compared with those of fibrous membranes 
prepared with low molecular weight PVA and by electrospun method. The results clearly shows that h-BNNS/PVA membranes display higher Young modulus and tensile strength than fibrous membranes ( $110 \mathrm{MPa}$ and 4.3MPa, respectively). ${ }^{12}$ However the fibrous membranes display higher elongation at break $57 \%$ compared to h-BN/PVA membranes ( 10\%).

\section{Membrane performances}

To characterize the performances of the membrane, gasliquid displacement porometry, water flux and particle rejection tests were also performed. The gas-liquid displacement porometry allows determining the surface pore size distribution and the mean pore size of the membranes. Fig. 9 shows the results of the pore size distribution of BNP-1h and BNP-3h membranes obtained by using this technique.

Table 1 Values of Young modulus, tensile strength and elongation at break ratio

\begin{tabular}{cccc}
\hline Sample & $\begin{array}{c}\text { Young modulus } \\
(\mathrm{MPa})\end{array}$ & $\begin{array}{c}\text { Tensile strength } \\
(\mathrm{MPa})\end{array}$ & $\begin{array}{c}\text { Elongation at } \\
\text { break } \\
(\%)\end{array}$ \\
\hline BNP-1h & $229 \pm 28$ & $7.3 \pm 1.4$ & $10.3 \pm 0.1$ \\
BNP-3h & $194 \pm 23$ & $5.2 \pm 0.8$ & $11.3 \pm 0.4$ \\
BNP-24h & $1180 \pm 31$ & $14.6 \pm 0.1$ & $7.8 \pm 0.2$ \\
PVA & $19 \pm 2$ & $42 \pm 4$ & $22.6 \pm 0.4$ \\
h-BNNS/PVA & $6.9 \pm 1.4$ & $21 \pm 3$ & $36.2 \pm 0.6$ \\
\hline
\end{tabular}

These results agree with SEM observations according to which the mean pore size of BNP-3h is smaller than those of BNP-1h. The BNP-3h membrane displays a mean pore size around $0.19 \pm 0.03 \mu \mathrm{m}$ while the BNP-1h displays higher pore size around $1.1 \pm 0.3 \mu \mathrm{m}$. It was impossible to conduct this characterization in BNP-24h because of its undefined porosity and to the fact water was not able to pass through the membrane. These results confirm that, the time the membranes were left to cure has strong influence on their morphology and pore size distribution. Results reported elswhere confirm the influence of the curing time or the pretreatments and the temperature on the polymer-based membrane structures. ${ }^{44-46}$

At a given pore size distribution, the membranes could be characterized for microfiltration membranes. The performance of the BNP-1h and BNP-3h to filter water was characterized by determining the flux versus the applied pressure by using solvent porometry. The flux is determined by the specific resistance of the membrane material under a given differential pressure across the membrane so that the flux increases with the operating area of the membrane and with the applied pressure. The water permeability results are shown in Table 2.

The BNP-1h membrane displays a high water flux around $2065 \mathrm{~L} \mathrm{~h}^{-1} \mathrm{~m}^{-2}$ bar $^{-1}$ in comparison to BNP-3h which displays a water flux of $87 \mathrm{~L} \mathrm{~h}^{-1} \mathrm{~m}^{-2}$ bar $^{-1}$. These results evidence that the membrane pore size distribution plays an important role in their performance to filter water. The water flux performance in BNP1h and BNP-3h membranes was followed for $6 \mathrm{~h}$ to verify the membrane stability. The results (Fig. S3) show that the membranes keep more than $90 \%$ of their performance after $6 \mathrm{~h}$ of water filtration. If the results are compared with those in the literature for PVA membranes produced by TIPS-LCST ${ }^{11}$, it is observed that the as-prepared h-BNNS/PVA membranes displays higher water permeability. The PVA membranes prepared by TIPS-LCST technique exhibit either too low (less than $1 \mathrm{~L} \mathrm{~h}^{-1} \mathrm{~m}^{-2}$ bar $^{-1}$ ) or too high (more than $10,000 \mathrm{~L} \mathrm{~h}^{-1} \mathrm{~m}^{-2}$ bar $\left.{ }^{1}\right)$ permeability values demonstrating the difficulty to prepare PVA membranes with controlled porosity. Besides, the fibrous membranes prepared by electrospun methods ${ }^{12}$ possess similar water permeability values (compared with BNP-3h membranes but the water flux for BNP-1h is much higher due to the increase in porosity. ${ }^{47}$ The addition of nanoaprticles into membranes aims to improve the hydrophilicity and anti-fouling resistance. The comparison of our h-BNNS/PVA membranes with other membranes containing nanoparticles such as polysulfone (PSf) with silica nanoparticles $\left(\mathrm{SiO}_{2}\right)$, shows that these nanocomposite membranes present
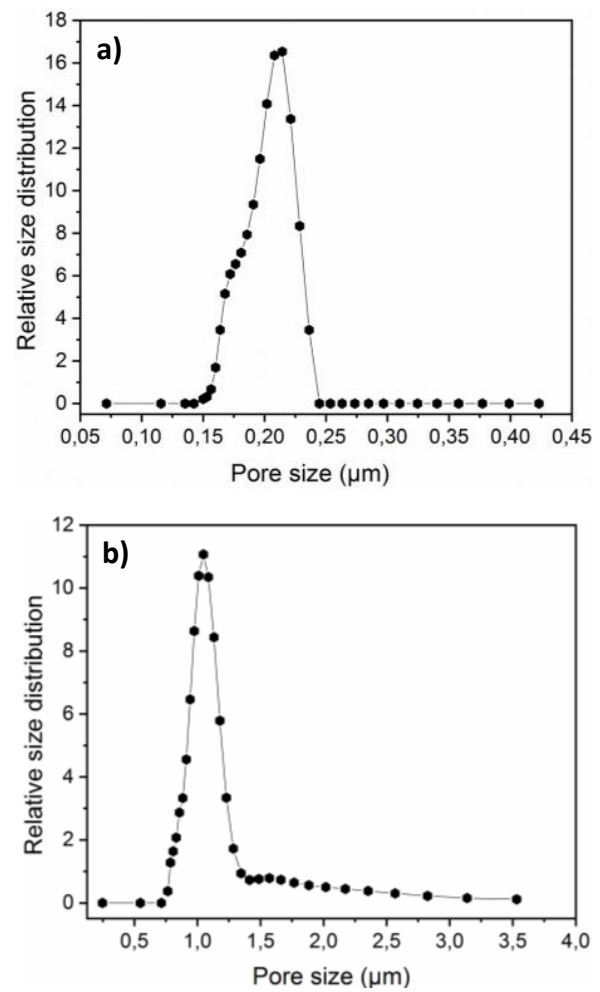

Fig. 9 Relative pore size distribution of a) BNP-1h b) BNP-3h obtained from gas-liquid displacement porometry

similar pore size in comaprison to our BNP-3h membranes, however $\mathrm{BNP}-3 \mathrm{~h}$ posses better flux than the $\mathrm{PSf} / \mathrm{SiO}_{2}$ membrane which display a water flux of only $17.3 \mathrm{~L} \mathrm{~h}^{-1} \mathrm{~m}^{-2}$ bar$1.48 \mathrm{~h}-\mathrm{BNNS} / \mathrm{PVA}$ membranes also presented better water flux in comparison to polyethersulfone membrane embedded with $\mathrm{TiO}_{2}$ coated multiwalled carbon nanotubes $\left(5.7 \mathrm{~L} \mathrm{~h}^{-1} \mathrm{~m}^{-2}\right.$ bar-1). ${ }^{49}$ Concerning the preparation of PVA-fibrous membranes, it is possible to control the fibers diameter but not the final membrane porosity. In this study, we developed for the first time a new concept on pore tuning for PVA-based membrane by easily controlling the parameters, such as curing time, during membrane preparation using Pickering emulsion templating.

To evaluate the ability of h-BNNS/PVA membranes to work as microfiltration filters, a particle rejection test using $0.1,1.2$ and $3 \mu \mathrm{m}$ polystyrene latex particles was made. First, the 
membrane permeability was tested using the dead-end cell by flushing MilliQ water at 1 bar for $30 \mathrm{~min}$. Then the cell was filled with the latex NPs solution and they were forced to pass through the membrane by applying a 0.4 bar of pressure.

Table 2 shows the rejection ratio of the BNP-1h and BNP-3h for the different latex NPs tested. The results show that the BNP$1 \mathrm{~h}$ membrane with a pore size distribution of $1.1 \mu \mathrm{m}$ could reject $3.8 \pm 0.1,85.7 \pm 0.2$ and $99.2 \pm 0.1 \%$ of latex NPs paticles sizing $0.1,1.2$ and $3 \mu \mathrm{m}$, respectively. These observation can be correlated to the pore data size, which indicates that the mean pore size of the membrane is $1.1 \mu \mathrm{m}$ with a size deviation of 0.3 $\mu \mathrm{m}$. The rejection rate for the $3 \mu \mathrm{m}$ particles is not $100 \%$, which could be explain by the plot of size distribution (Fig. 9b) which displays a little shoulder between 1.5 and $3.5 \mu \mathrm{m}$.

Table 2 Water flux permeability and rejection ratios of BNP-1h and BNP-3h membranes for different sizes of latex NPs

\begin{tabular}{ccccc}
\hline Sample & $\begin{array}{c}\text { Water flux } \\
\left(\mathrm{L} \mathrm{h}^{-1} \mathrm{~m}^{-2} \mathrm{bar}^{-1}\right)\end{array}$ & $\begin{array}{c}\text { \% Rejection } \\
\text { Latex NPs } \\
100 \mathrm{~nm}\end{array}$ & $\begin{array}{c}\text { \% Rejection } \\
\text { Latex NPs } \\
1.2 \mu \mathrm{m}\end{array}$ & $\begin{array}{c}\text { \% Rejection } \\
\text { Latex NPs } \\
3 \mu \mathrm{m}\end{array}$ \\
\hline BNP-1h & $2065 \pm 74$ & $3.8 \pm 0.1$ & $85.7 \pm 0.2$ & $99.2 \pm 0.1$ \\
BNP-3h & $87 \pm 6$ & $76.4 \pm 0.2$ & $99.7 \pm 0.2$ & - \\
\hline
\end{tabular}

The results for the BNP-3h membranes with a pore size distribution of $0.19 \mu \mathrm{m}$ show that it could reject $76.4 \pm 0.2$ and $99.7 \pm 0.2 \%$ of latex NPs particles sizing 0.1 and $1.2 \mu \mathrm{m}$, respectively. These observations are well correlated with the pore size distribution of the membrane. It should be noted for $100 \mathrm{~nm}$ latex NPs, they could easily get into the porous membrane as many of the pores on the surface were greater than $0.19 \mu \mathrm{m}$. However, when the particles penetrate deeper, the effective pore size in the flow direction becomes smaller due to the winding road shape of the channels making the flushing of particles more difficult. The permeability was tested after the particle rejection test and the membranes did not significaly reduce their performance. The rejection efficiency of nanoparticles in BNP-3h membrane is higher (99.7\%) than in other PVA-based membranes.

For example, the PVA-based fibrous membranes with an average pore size of $15.61 \mu \mathrm{m}$, leads to a rejection efficiency of $96 \%$ for $0.5 \mu \mathrm{M}$ particles; this rejection efficiency was already smaller compared to other electrospun melt membranes. ${ }^{50}$ b)

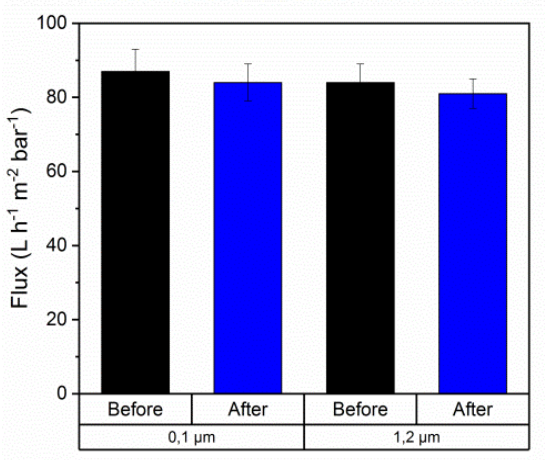

Fig. 10 Corresponding fluxes of a) BNP-1h and b) BNP-3h membranes before and after performing particle rejection tests.

The water permeability of BNP-1h and BNP-3h was performed after particle rejections test to verify the membrane performance due to its relevance to the repeatability and recyclability for industrial applications. The results (Fig. 10) show that the membranes did not significantly reduce their water permeability performances after performing particle rejection test. The membranes pore size might also be tuned apart from the curing time by playing with polymer and stabilizer concentrations as well as the oil/water ratios of the emulsion or the casting parameters. Playing with all the parameters, it could be possible to obtain a membrane with defined porosity and permeability to filter a large set of targeted compounds. This strategy could be applied to produce other polymer or ceramic-based membranes. These microporous membranes could have a potential application for the pre-treatment of wastewater reuse in agricultural or food industries where pesticides and pharmaceutical compounds are present. ${ }^{51}$ Indeed, wastewater treatment plants (WWTPs) are not able to efficiently remove many organic contaminants and pathogens. ${ }^{52}$

\section{Experimental}

h-BN was purchased from Saint Gobain (95\% purity, 325 mesh, $3 \mu \mathrm{m}$ particle size), PVA ( $\mathrm{Mw}=27000 \mathrm{~g} / \mathrm{mol}^{-1}$, degree of hydrolysis 98), ethyl benzoate (purification $\geq 99 \%, \mathrm{Mw}=150 \mathrm{~g}$ $\mathrm{mol}^{-1}$ and density $=1.045 \mathrm{~g} \mathrm{~mL}^{-1}$ ), glutaraldehyde (GTA) (Grade I, $25 \%$ in $\mathrm{H}_{2} \mathrm{O}$ ) and hydrochloric acid (ACS reagent, $\geq 37 \%$ ) were purchased from Sigma Aldrich. Polystyrene latex nanoparticles, also known as latex beads, with different size $(0.1,1.2$ and $3 \mu \mathrm{m})$ were purchased form Thermo Fisher Scientific. All chemicals were used without further purification. In all the experiments, deionized pure water (18 $\mathrm{M} \Omega$ ) was used.

\section{Fabrication of exfoliated h-BNNS}

In a typical method, h-BNNS were fabricated by liquid phase exfoliation with the assistance of an ultrasounds device (model SONOPLUS HD 3100, 100W, $20 \mathrm{kHz}$ ) with a $3 \mathrm{~mm}$ diameter microtip (MS73). Basically, $1.0 \mathrm{~g}$ of pristine $\mathrm{h}-\mathrm{BN}(3 \mu \mathrm{m})$ was added into $100 \mathrm{~mL}$ of water and then sonicated for 1 hour at 65 $\%$ amplitude with pulse off/on $0.5-1 \mathrm{~s}$. After the sonication, the whitish suspension was allowed to rest for $30 \mathrm{~min}$, and then the supernatant was collected through centrifuging at $3000 \mathrm{rpm}$ for $15 \mathrm{~min}$. The h-BNNS product was collected by filtration and then dried at $60^{\circ} \mathrm{C}$ before use. 


\section{h-BNNS/PVA emulsions preparation}

Pickering emulsions stabilized with h-BNNS and PVA were prepared following a simple two-steps sonication protocol. First, exfoliated h-BNNS ( 2 wt.\%) was suspended in water and sonicated for $15 \mathrm{~min}$ at $65 \%$ amplitude with pulse off/on 0.5 $1 \mathrm{~s}$ using ultrasounds device in order to ensure its good dispersion. Then, the solution was heated up to $80{ }^{\circ} \mathrm{C}$ under magnetic stirring and PVA (15 wt.\%) was added slowly, to avoid the formation of lumps, to the h-BNNS aqueous suspension and kept for $4 \mathrm{~h}$ until the total polymer dissolution. After, ethyl benzoate was added to the as-prepared h-BNNS/PVA suspension with ratio oil/water 0.25 . A homogeneous whitish emulsion was formed after sonication with the same equipment for $15 \mathrm{~min}$ at $65 \%$ amplitude and pulse off/on $0.5-1 \mathrm{~s}$.

\section{h-BNNS/PVA porous membranes preparation}

The membranes were prepared by casting the homogeneous $h$ BNNS/PVA solution onto glass support with $500 \mu \mathrm{m}$ thickness and speed of $40 \mathrm{~cm} \mathrm{~s}^{-1}$. A homogeneous white film is obtained and dried at room temperature for different curing times before crosslinking them. The films were cross-linked at room temperature by direct immersion into a bath composed of ethanol (96\%) containing a 3 wt.\% GTA ( $25 \%$ in $\mathrm{H}_{2} \mathrm{O}$ ) solution and $1 \mathrm{wt} . \% \mathrm{HCl}(37 \%)$. Ethanol has the advantage to be miscible with GTA but is considered as a non-solvent for PVA. This step has two functions; first, it allows the crosslinking reaction between PVA and GTA catalysed by $\mathrm{HCl}$ and second it enables the ethyl benzoate extraction. The membrane was slowly selfseparated from the support when it was introduced into a water bath to wash. Additional washings were conducted in water and ethanol baths to ensure the removal of GTA and ethyl benzoate residues from the membranes. Finally, the membranes were kept in a water bath to conserve them. The membranes were labelled as BNP-x $h(x=1,3$ or $24 h$ ) depending on the time they were cured before their crosslinking. More details concerning the strategy of formation of porosity in membranes is given in the supporting information.

\section{Structural and chemical characterization}

The morphology of the membrane, both cross-section and surface, has been observed using a Hitachi S4800 scanning electron microscopy system (SEM). For the analysis, the samples were first coated with platinum using an ion sputter coater. The Fourier transform infrared (FTIR) spectra were recorded with a NEXUS instrument equipped with an attenuated total reflection (ATR) accessory in the frequency range of $600-4000 \mathrm{~cm}^{-1}$. The ATR-FTIR spectra were recorded with a resolution of $4 \mathrm{~cm}^{-1}$, and the signals were averaged from 32 scans. The X-ray diffraction (XRD) patterns of cross-linked hBNNS/PVA membranes were recorded using a PANalytical Xpert powder XRD system with $\mathrm{Cu} \mathrm{K} \alpha$ radiation, a scan speed of $2^{\circ}$ $\min ^{-1}$, a $2 \theta$ range of between 10 and $70^{\circ}$, and a step rate of $0.02^{\circ}$ per second. Thermal behaviour of the as prepared membranes was examined by a thermogravimetric analyser (model TA instruments TGA G500) from $20^{\circ} \mathrm{C}$ to $800^{\circ} \mathrm{C}$. A heating rate of $10^{\circ} \mathrm{C} / \mathrm{min}$ was used under air atmosphere and a flow rate of $60 \mathrm{~mL} / \mathrm{min}$. Dry sample weighing about $10 \mathrm{mg}$ was used. The thermal transition behaviour of the membranes was determined by a differential scanning calorimeter (model TA instruments DSC Q20) equipped with a RCS90 cooling system, from $20^{\circ} \mathrm{C}$ to $200^{\circ} \mathrm{C}$. A heating rate of $10^{\circ} \mathrm{C} / \mathrm{min}$ was used under nitrogen atmosphere and at flow rate of $50 \mathrm{~mL} / \mathrm{min}$. The samples weight was about $3 \mathrm{mg}$ and they were sealed into an aluminium capsule for the analysis. Water contact angles (WCA) were measured using a B-CAM-21-BW (CCCIR) monochrome camera and a Led R60 lamp purchased from CONRAD. For each sample, 3.0 $\mu \mathrm{L}$ of ultrapure water was deposited on the membranes using a needle. The images were recorded by One Touch Grabber software and treated using ImageJ software. The mechanical properties of the cross-linked h-BNNS/PVA membranes were characterized using the dynamic mechanical analysis system (Metravib 50N) at a tensile testing speed (crosshead speed) of $0.4 \mathrm{~mm} \mathrm{~min}{ }^{-1}$. Young's modulus of the membranes was calculated from the elastic region of the stress-strain curves.

\section{Swelling kinetics}

The films were cut into $1 \times 1 \mathrm{~cm}^{2}$ pieces and dried at vacuum for $24 \mathrm{~h}$. The initial weight of the membranes was recorded and equilibrated at ambient temperature in $5 \mathrm{~mL}$ of deionized water. The swelling kinetics was evaluated periodically by measuring the weight of the films using a microbalance (Sartorius CPA225D with an accuracy of $0.00001 \mathrm{~g}$ ) after gently blotting the surface with a tissue paper.

The swelling ratio (\%) was evaluated as:

$\mathrm{SWR}=\frac{W_{w}-W_{D}}{\mathrm{~W}_{D}} \cdot 100$ Equation 1

where, $W_{D}$ is the weight of the dry membranes and $W_{W}$ is the weight of the membrane after wetting. Each data point shown is the average value of three replicates.

\section{Pore size determination}

The membrane pore size and their distribution were obtained by liquid-gas displacement porometry. The measurements were carried out using a PRM-2000-LL-R porometer (IFTSFrance). In this method, the pores of the sample were first filled with water during a wetting step. Then, nitrogen gas was applied through the membrane, and the flow rate was measured as a function of the applied pressure. When a straight line is obtained between nitrogen flow and pressure, all pores have been opened. Pore dimension patterns are calculated by applying Laplace's law (Equation 2). Each data point shown is the average value of three replicates.

$\Delta \mathrm{P}=\frac{4 \gamma \cos \theta}{\mathrm{D}}$ Equation 2

where $\Delta P$ is the differential of applied pressure, $V$ is the interfacial tension of water, $\theta$ is the contact angle between the material and the liquid and $D$ is the pore diameter.

\section{Water permeability measurement}

The membrane permeability was measured by solvent permeability; the experiments were carried out using a PRM- 
2000-LL-R porometer (IFTS-France) with a membrane-active surface area of $2.27 \mathrm{~cm}^{2}$. The membranes were already wet by introducing them into a water bath during $24 \mathrm{~h}$. The pure water flux $\left(J_{P W}\right)$ was measured for each membrane by circulating pure water through the membrane system using an applied pressure range of 0-1 bar, each point was obtained measuring the flow passing through the membrane during $60 \mathrm{~s}$.

The $\mathrm{J}_{\mathrm{PW}}\left(\mathrm{I} \mathrm{h}^{-1} \mathrm{~m}^{-2}\right)$ was calculated using the following formula:

$J P W=\frac{Q}{A} \quad(L / h \cdot m 2)$

Equation 3

where $Q(L / h)$ is the amount of water that passed through the membrane and $A\left(\mathrm{~m}^{2}\right)$ is the membrane area. The permeability was determined from the slope of the linear variation of $J_{P W}$ versus the applied pressure.

\section{Polystyrene Latex Particle Rejection Test}

To corroborate the results of the pore sizes given by porometry, the membranes pore sizes were estimated by polystyrene latex particle rejection experiments. Frontal filtration experiments were carried out using a stirred dead-end cell (Amicon 8050, Millipore Corporation) with a membrane-active surface area of $2.27 \mathrm{~cm}^{2}$. The membranes were first compacted by filtering pure water up to 1 bar until a constant flux was observed. Then, the polystyrene particles were monodispersed polystyrene latex particles with diameters of $0.1,1.2$ and $3 \mu \mathrm{m}$. The feed solution was prepared by adding latex NPs to $15 \mathrm{~mL}$ ultrapure water solution. The feed was added into the cell and forced to permeate through the membranes using an applied pressure of 0.4 bars. The permeate solution and the feed solution were collected after filtration into a vial and later analysed by dynamic light scattering (DLS) to estimate the amount of latex NPs passed through the membrane. Particle rejection was calculated using the following equation:

$\% \mathrm{R}=\frac{I_{P}}{I_{R}} \cdot 100$

Equation 4

where $I_{p}$ is the intensity of counts of the permeate solution and $I_{R}$ is the intensity of counts of feed solution retained in the cell. Each data point shown is the average value of three replicates. The membrane permeability was followed after each experiment to verify the membrane performance.

\section{Conclusions}

A novel strategy to produce porous membranes based on PVA polymer has been developed using emulsion templating. This method can be considered as sustainbale offering a synthesis using mainly water as solvent and non-harmful reactants. Furthermore, it avoids sintering steps and prevents waste generation. In a first step, Pickering emulsions based on $\mathrm{h}-$ BNNS/PVA mixtures were prepared, and in a second step a porous membrane was produced after casting and crosslinking with GTA. The membrane curing time has been found to play a role in its final morphology. The membranes which were left to cure for shorter duration present higher pore size as well as a

more pronounced hydrophilic behaviour due to the lower crosslinking effectiveness. As a result of these parameters, the swelling ratio is also higher for the BNP-1h. The h-BNNS/PVA membranes based on emulsion templating present a mean pore size of $1.1 \mu \mathrm{m}$ and $0.19 \mu \mathrm{m}$ when they were cured for 1 and $3 \mathrm{~h}$, respectively. Due to its higher porosity, the BNP-1h displays water permeability 20 times higher than BNP-3h membrane. The interest of BNP-3h membrane remains in its particle rejection performance; it was able to reject more than $76 \%$ of latex NPs sizing $0.1 \mu \mathrm{m}$ and $99.7 \%$ of the particles sizing $1.2 \mu \mathrm{m}$. A new concept of pore tuning by easily controlling parameters, such as the curing time during membrane preparation using Pickering emulsion templating has been developed in this work for PVA-based membranes. The obtained membranes display higher efficiency in water filtration and particle rejection than other PVA-based porous membranes obtained by electrospun methods. This new strategy opens a new route for the development of porous membranes with controllable pore size from hydrophilic polymers for microfiltration applications.

\section{Conflicts of interest}

There are no conflicts to declare.

\section{Acknowledgements}

The work was financially supported by the French National Agency (ANR) through the LabEx CheMISyst (ANR-10-LABX-0501).

\section{Notes and references}

1
A. Pruss-Ustun and W. H. Organization, 2008.

G. M. Geise, H. S. Lee, D. J. Miller, B. D. Freeman, J. E. McGrath and D. R. Paul, Journal of Polymer Science Part B: Polymer Physics, 2010, 48, 1685-1718.

F. Zaviska, P. Drogui, A. Grasmick, A. Azais and M. Héran, Journal of Membrane Science, 2013, 429, 121-129.

W. Xiao, L. Zhao, Y. Gong, J. Liu and C. Yan, Journal of Membrane Science, 2015, 487, 221-228.

S. Pina, J. M. Oliveira and R. L. Reis, Advanced Materials, 2015, 27, 1143-1169.

Q. G. Zhang, C. Deng, F. Soyekwo, Q. L. Liu and A. M. Zhu, Advanced Functional Materials, 2016, 26, 792-800.

M. S. S. A. Saraswathi, D. Rana, P. Vijayakumar, S. Alwarappan and A. Nagendran, New Journal of Chemistry, 2017, 41, 14315-14324.

A. Khalid, A. A. Al-Juhani, O. C. Al-Hamouz, T. Laoui, Z. Khan and M. A. Atieh, Desalination, 2015, 367, 134-144. Y. Hu, Z. Lü, C. Wei, S. Yu, M. Liu and C. Gao, Journal of Membrane Science, 2018, 545, 250-258.

Y. Zhang, H. Li, H. Li, R. Li and C. Xiao, Desalination, 2006, 192, 214-223.

O. M'barki, A. Hanafia, D. Bouyer, C. Faur, R. Sescousse, U. Delabre, C. Blot, P. Guenoun, A. Deratani and D. Quemener, Journal of Membrane Science, 2014, 458, 225-235. 
K. Yoon, B. S. Hsiao and B. Chu, Journal of Membrane Science, 2009, 338, 145-152.

Z. Chen, C. Zhao, E. Ju, H. Ji, J. Ren, B. P. Binks and X. Qu, 39 Advanced Materials, 2016, 28, 1682-1688.

Y. Zhang, Y. Chen, Y. Shen, Y. Yan, J. Pan, W. Shi and L. Yu, ChemPlusChem, 2016, 81, 108-118.

J. Frelichowska, M.-A. Bolzinger, J.-P. Valour, H. Mouaziz, J. Pelletier and Y. Chevalier, International journal of pharmaceutics, 2009, 368, 7-15.

Z. Li, M. Xiao, J. Wang and T. Ngai, Macromolecular rapid communications, 2013, 34, 169-174.

17. J. L. Robinson, R. S. Moglia, M. C. Stuebben, M. A. McEnery and E. Cosgriff-Hernandez, Tissue Engineering Part A, 2014, 20, 1103-1112.

J. M. Hughes, P. M. Budd, K. Tiede and J. Lewis, Journal of Applied Polymer Science, 2015, 132.

T. Skale, L. Hohl, M. Kraume and A. Drews, Journal of Membrane Science, 2017, 535, 1-9.

R. T. Woodward, D. W. Fam, D. B. Anthony, J. Hong, T. O. McDonald, C. Petit, M. S. Shaffer and A. Bismarck, Carbon, 2016, 101, 253-260.

N. R. Cameron, Polymer, 2005, 46, 1439-1449.

M. Ziminska, N. Dunne and A. R. Hamilton, ACS applied materials \& interfaces, 2016, 8, 21968-21973.

E. Aram and S. Mehdipour-Ataei, International Journal of Polymeric Materials and Polymeric Biomaterials, 2016, 65, 358-375.

V. H. Bartl and W. Von Bonin, Macromolecular Chemistry and Physics, 1962, 57, 74-95.

K. J. Lissant and K. G. Mayhan, Journal of colloid and interface science, 1973, 42, 201-208.

J. M. Williams and D. A. Wrobleski, Langmuir, 1988, 4, 656-662.

V. O. Ikem, A. Menner, T. S. Horozov and A. Bismarck, Advanced Materials, 2010, 22, 3588-3592.

Y. Yang, Y. Ning, C. Wang and Z. Tong, Polymer Chemistry, 2013, 4, 5407-5415.

H. Xu, X. Zheng, Y. Huang, H. Wang and Q. Du, Langmuir, 2015, 32, 38-45.

Y. Zhao, H. Wang, X. Song and Q. Du, Macromolecular Chemistry and Physics, 2010, 211, 2517-2529.

X. Li, G. Sun, Y. Li, J. C. Yu, J. Wu, G.-H. Ma and T. Ngai, Langmuir, 2014, 30, 2676-2683.

B. Neirinck, J. Fransaer, O. Van der Biest and J. Vleugels, Advanced engineering materials, 2007, 9, 57-59.

K.-Y. A. Lin, H. Yang and C. Petit, Journal of colloid and interface science, 2015, 438, 296-305.

M. Tang, X. Wang, F. Wu, Y. Liu, S. Zhang, X. Pang, X. Li and H. Qiu, Carbon, 2014, 71, 238-248.

S. Nagarajan, D. Abessolo Ondo, S. Gassara, M. Bechelany, S. Balme, P. Miele, N. S. Kalkura and C. Pochat-Bohatier, Langmuir, 2017.

D. Gonzalez Ortiz, C. Pochat-Bohatier, J. Cambedouzou, S. Balme, M. Bechelany and P. Miele, Langmuir, 2017, 33, 13394-13400.

Y. Yao, Z. Lin, Z. Li, X. Song, K.-S. Moon and C.-p. Wong, Journal of Materials Chemistry, 2012, 22, 13494-13499.
C. Zhao, X. Xu, J. Chen and F. Yang, Journal of Environmental Chemical Engineering, 2013, 1, 349-354. A. Razmjou, A. Resosudarmo, R. L. Holmes, H. Li, J. Mansouri and V. Chen, Desalination, 2012, 287, 271280.

40 L. Cao, S. Emami and K. Lafdi, Materials Express, 2014, 4, 165-171.

41 K. Marsh, M. Souliman and R. B. Kaner, Chemical Communications, 2015, 51, 187-190.

J. Z. Manapat, J. D. Mangadlao, B. D. B. Tiu, G. C. Tritchler and R. C. Advincula, ACS applied materials \& interfaces, 2017, 9, 10085-10093.

43 A. Ahmad, N. Yusuf and B. Ooi, Desalination, 2012, 287, 35-40.

44 J. Albo, J. Wang and T. Tsuru, Journal of membrane science, 2014, 449, 109-118.

J. Albo, J. Wang and T. Tsuru, Journal of membrane science, 2014, 453, 384-393.

J. Albo, H. Hagiwara, H. Yanagishita, K. Ito and T. Tsuru, Industrial \& Engineering Chemistry Research, 2014, 53, 1442-1451.

47 X. Wang, D. Fang, K. Yoon, B. S. Hsiao and B. Chu, Journal of Membrane Science, 2006, 278, 261-268.

48 48. A. Ahmad, M. Majid and B. Ooi, Desalination, 2011, 268, 266-269.

49 V. Vatanpour, S. S. Madaeni, R. Moradian, S. Zinadini and B. Astinchap, Separation and purification technology, 2012, 90, 69-82.

$50 \quad$ X. Li, W. Yang, H. Li, Y. Wang, M. M. Bubakir, Y. Ding and Y. Zhang, Journal of Applied Polymer Science, 2015, 132.

51 S. Rodriguez-Mozaz, M. Ricart, M. Köck-Schulmeyer, H. Guasch, C. Bonnineau, L. Proia, M. L. de Alda, S. Sabater and D. Barceló, Journal of hazardous materials, 2015, 282, 165-173.

52 A. Jelic, M. Gros, A. Ginebreda, R. Cespedes-Sánchez, F. Ventura, M. Petrovic and D. Barcelo, Water research, 2011, 45, 1165-1176. 